DOI: $10.2478 /$ ausfm-2014-0034

\title{
Local Sensorium, Local Cinema: György Pálfi's Sensuous Body Politics
}

\author{
György Kalmár \\ University of Debrecen (Hungary) \\ E-mail: gykalmar@yahoo.com
}

\begin{abstract}
György Pálfi’s Hukkle (2002) and Taxidermia (2006) establish markedly unique cinematic styles and richly sensorial life-worlds, which function in both films as counter-discourses opposing official history, hegemonic ideologies, and conventional patterns of (cinematic) understanding. In the present study I analyse the ways Pálfi's films communicate through non-symbolic meaning, bodily discourses, and a heavy reliance on the multisensory evocation of the local sensorium (Marks) and the local habitus (Bourdieu) so as to create significance on the margins of established, hegemonic systems of meaning, cinema, ideology and identity.
\end{abstract}

Keywords: György Pálfi, Hukkle, Taxidermia, local sensorium, local habitus.

The present paper originates in a personal experience that is as intercultural as multisensory. Two years ago I had the good fortune to spend a six months' research trip in Andalucia. When I came back after half a year's absence and my plane landed in the late summer of the Eastern-European temperate zone, I went through an experience that I can only compare to that of the narrator of Proust's A la reserche de temps perdu upon tasting the Madeleine reminding him of the days he spent in Combray as a child. I was picked up by a friend at the airport and went to a summer cottage. When I got out of the car, I suddenly realised that I had been really away: these particular smells of the forests, this chill of the evening, these sounds of nature, this kind of blueness of the sky were home, sensory experiences completely missing from the hot, sunny Mediterranean coasts of Andalucia. The concept of home appeared through an invasion of the senses (so as to use Proust's expression): it was first my body that knew that I was home.

It was this experience that first 'brought home' to me the idea that ways of being-in-the-world and ways of seeing the world, that is, sensuous impressions and key metaphors, bodily reactions, and historical experiences may be intimately interlaced. The initial hypothesis of the present paper is that these interactions 
may be perceivable in cinema as well: Hungarian cinema may have a different sensuousness than Spanish cinema, for example. They may mobilize different senses, rely on different sensoriums, and evoke these for different (ideological, political, aesthetic) purposes. In this paper my intention is to show how certain pieces of contemporary Hungarian cinema - specifically the films of György Pálfi - rely on physically stored collective memories and evoke a culturally specific, local sensorium in order to undermine the ideologically laden grand narratives of a homogenized, official History.

\section{The Local Sensorium}

In his seminal work, The Logic of Practice, Pierre Bourdieu emphasises the bodily embedded nature of one's relation to the world. Following Durkheim, who called attention to the way past experiences of a community may be stored unconsciously and may influence future social and individual behaviour, Bourdieu introduces the concept of habitus: "The habitus, a product of history, produces individual and collective practices - more history - in accordance with the schemes generated by history. It ensures the active presence of past experiences, which, deposited in each organism in the form of schemes of perception, thought and action, tend to guarantee the 'correctness' of practices and their constancy over time, more reliably than all formal rules and explicit norms" (1990, 54). Bourdieu's habitus is a sort of imprint of historical experience of a certain group, a cluster of unconscious knowledge that is "constituted in practice" $(1990,52)$ and stored in the body: "Practical belief is not a 'state of mind,' still less a kind of arbitrary adherence to a set of instituted dogmas and doctrines ('beliefs'), but rather a state of the body. Doxa is the relationship of immediate adherence that is established in practice between a habitus and the field to which it is attuned, the pre-verbal taking-for-granted of the world that flows from practical sense. Enacted belief, instilled by the childhood learning that treats the body as a living memory-pad, [...] a repository for the most precious values, is the form par excellence of the 'blind or symbolic thought' [...] which is the product of quasibodily dispositions" (Bourdieu 1990, 68). In other words, people with the same habitus (which, in Bourdieu's thought, is equal to one "group" of people) share more or less similarly conditioned "schemes of perception, thought and action" (1990, 54): they do not only think similarly, but also sense similarly.

It is not only Bourdieu, however, who points out the possibility of cultural or geographical specifications of the senses, and the interconnection of cognitive and 
sensory schemas. According to Lakoff and Johnson, metaphors actively shape the ways we live or experience. In their seminal work, Metaphors We Live By, they argue that: "It is as though the ability to comprehend experience through metaphor were a sense, like seeing or touching or hearing, with metaphors providing the only ways to perceive and experience much of the world. Metaphor is as much a part of our functioning as our sense of touch, and as precious" $(1980,239)$.

In this sense, I would argue, one can distinguish between the cinemas of different cultures not only on basis of the filmed material (the actors, dresses, locations, etc.), or cinematic techniques (like certain narrative techniques characteristic or French cinema, or the way the long take is used by Tarr or Jancsó), but also on basis of "the feel" of these films: the way the camera looks may be as significant as the look of the actors and actresses, the way sound is used may be as significant as the particular language spoken. ${ }^{1}$ This "feel," these patterns of perception and view learned from both life and films - if one is to believe Bourdieu, Lakoff, and Johnson - may be stored so deeply in one's cognitive and sensory patterns, mind and body, that it seems completely natural, it is (in Bourdieu's often used expression) history turned into nature.

Due to the recent academic interest in sensory experience in different cultures in such diverse fields as sensorial anthropology, cultural psychology, and cultural phenomenology, it can be safely assumed today that "larger abstract cultural ideas can affect the structure of the sensorium" (Geurts 2002, 6), therefore we can talk about ,the culturally specific construction of our own sensorium” (Geurts 2002, 6) on strictly scientific grounds, without any kind of essentialist conceptualization of "Westernness" or nationhood. Without attempting to outline this wide and colourful academic field, let me simply quote one fairly recent study, the insights of which strongly influence my own focus on the sensorial and bodily aspects of contemporary Hungarian cinema, Kathryn Linn Geurts's Culture and the Senses: "I believe that in a cultural community's sensorium we find refracted some of the values that they hold so dear that they literally make these themes or these motifs into 'body.' In other words, a cultural community's sensory order reflects aspects of the world that are so precious to the members of that community that (although they remain largely unconscious and habitual) they are the things that children

1 For a recent take on the old question of national cinemas, see Gábor Gulyás's interview with András Bálint Kovács made for and displayed at the What is Hungarian? Contemporary answers exhibition in Kunsthalle, Budapest (2 August - 14 October, 2012). Kovács here affirsms the possibility of distinguishing between different national cinemas, but he is sceptical about the existence of a unique Hungarian cinematic tradition. 
growing up in this culture developmentally come to carry in their very bodies. So the senses, I believe, are ways of embodying cultural categories, or making into body certain cultural values or aspects of being that the particular cultural community has historically deemed precious and dear" (Geurts 2002, 10).

I propose to take Geurts's ideas one step further and extend her concept of the body (in which a given cultural community's values are carried) to the cinematic body as well: I argue that a cultural community's cinema may carry patterns of perception, schemas of sensation, and ways of being-in-the-world very similarly as living bodies do. As Laura U. Marks's sensitive analyses of intercultural cinema in The Skin of the Film clearly show, when one watches films made by people belonging to other cultural communities (with different habitus), one has a chance to encounter a different sensorium, a life-world where the senses operate and are systemized in different ways.

\section{Pálfi’s Sensuous Counter-Histories}

I consider the theoretical possibilities of such different sensorial systems significant for the present study because in my opinion György Pálfi's two awardwinning films that I wish to analyse here establish markedly unique cinematic styles and sensorial life-worlds, which function in both films as counter-discourses opposing official history, hegemonic ideologies, and conventional patterns of (cinematic) understanding. Pálfi, in other words, tends to communicate in these films through sensory impressions, non-symbolic meaning and bodies, so as to create significance on the margins of established, hegemonic systems of meaning, ideology, and identity.

As I have elaborated in more detail in What the Body Remembers, the importance of counter-memory, and such destabilization or bypassing of official History (understood as an idealized and homogenized narrative that excludes marginal voices) is particularly significant in case of such smaller nations as Hungary. These strategies of counter-memory and the reliance on the local sensorium may be crucial in the identity-politics of losers of historical conflicts, peoples occupied, colonised, exploited by larger forces (as it happened with Hungary with respect to the Ottoman-Turkish, the Habsburg, and the Soviet Empires), as in such situations "official" History was often a means of oppression and ideological brain-washing. Hungary's traumatic past, and centuries of occupation by foreign forces definitely seem to be connected with such characteristics of its habitus as the incredulity towards grand historical narratives, the way most 
historical events and figures are subject to dispute and controversy, the way typical historical roles (such as hero, victim, or traitor) are often mixed, and the sceptical approach to idealized images and narratives.

The strategies of Hukkle and Taxidermia share some common characteristics in this respect, but they are not identical. Hukkle is set in a nameless Hungarian village, a sort of heterotopias (in the Foucauldian sense), on the margins of history and civilization. Verging on the experimental, and combining "Nat-Geo" style documentary (of people, plants, animals, and sensuously rich inanimate phenomena) with the crime genre, Hukkle creates a film text in which conceptual, symbolic, and narrative meanings are pushed to the background for the sake of sensuous overabundance. There is no audible dialogue in the film, which clearly limits the symbolic register, and the elements of the narrative are scattered among multisensory images of nature. Hukkle operates a complex, slightly experimental strategy that dislocates the humanist tradition of representation. The human figure is no longer the most important element of the frame, it is often too close or too far, medium shots are tellingly rare [Figs. 1-2]. This strategy undermines the hegemony of the human being (understood also as a culturally and historically specific figuration): the human figure is turned into a part of nature (when shown from the distance) or a phenomenal object (old hand, wrinkles on the face, young fingers). Following a Copernican or Darwinian approach that removes the human being from the centre of the story and the picture, and makes it an accidental detail or a marginal figure, the film also challenges traditional European iconography (together with its ideological apparatus). Hukkle often evokes inhuman perspectives: the subject of the gaze is often an animal [Fig. 3], or simply the curious, contemplative inhuman camera that operates without moral or value judgements, thirst for drama, or need of psychological motivation. The narrative of Hukkle (if there is one) involves the wives of the village systematically poisoning their husbands. Yet, their motivations for this is never clearly explained, the human characters do not show any sign of "human" sentiment, they do not cry when someone dies, do not show fear when poisoned. They simply go by their routines (like the animals represented), do their duties, live, work, cook, eat, and die in a most casual manner. Thus, the film "silences" what one could conventionally call the "human" aspect. This void, the lack of controlled narrative and symbolic meaning, however, is filled by a richness of phenomenologically sensitive multisensory images. Hukkle seems to deliberately avoid the controlled mastery of cinematic meaning practiced in what Laura U. Marks calls optical visuality, and favours haptic images instead. According to 
Marks, "The ideal relationship between viewer and image in optical visuality tends to be one of mastery, in which the viewer isolates and comprehends the objects of vision. The ideal relationship between viewer and image in haptic visuality is one of mutuality, in which the viewer is more likely to lose herself in the image, to lose her sense of proportion" $(2000,184)$.

In my opinion, the strongly phenomenological, sensuous film-text of Hukkle does indeed manage to make the spectator "lose herself in the image," moreover, with this loss (of oneself and one's sense of proportion) a whole tradition of cinematic meaning and interpretation may be lost as well (a question I will shortly come back to). What seems most crucial at this point is that these sensuous, haptic images [Fig. 4] supply rich multisensory impressions without turning the signified into represented objects: it often takes a considerable time for the spectator to realise what it is that one sees. The time gap between the sensorial impression and the realization of what "thing" exactly is shown, between an image and the concept, impression and idea, opens a space for a noncontrolled, non-human(istic), non-optical, non-narrative, and non-conceptual cinematic meaning, which is also affective and bodily. Marks's description of haptic, intercultural cinema suits very well this cinematic modus operandi: "By appealing to one sense in order to represent the experience of another, cinema appeals to the integration and commutation of sensory experience within the body. Each audiovisual image meets a rush of other sensory associations. Audiovisual images call up conscious, unconscious, and nonsymbolic associations with touch, taste, and smell, which themselves are not experienced as separate. Each image is synthesized by a body that does not necessarily divide perceptions into different sense modalities" $(2000,222)$.

Though Pálfi's later film Taxidermia seems to share the intention to side-track established, hegemonic narratives, and conventional ways of interpretation with the use of the body and sensuousness, its cinematic strategies are somewhat different. Taxidermia clearly tells stories: its three parts tell the stories of three generations of Hungarian men. The story of the grandfather is a story of a sexobsessed, half-wit Marosgovány, a soldier at an army outpost (in the middle of nowhere) in the Second World-War; that of the father is about the life of the fasteating (almost) champion Balatony Kálmán, set in the post-1945 Soviet-occupied Hungary; and the last part is about the son, Balatony Lajos(ka), the skinny, pale taxidermist son of the huge fast-eater, living in the bleak world of contemporary consumer society, the son who finally stuffs both his father and himself, turning their bodies into works of art, bodily monuments of a traumatic past. 
Whereas Hukkle was set in the heterotopic, liminal space of a nameless Hungarian village where narratives break up and human beings disappear, Taxidermia does not get rid of either storytelling or recognizable historical times, we may know (more or less) which era is revisited. The film also involves dialogue, and relies strongly on symbolic and narrative elements. On the other hand, Taxidermia sidetracks the grand narratives of official history by the inclusion of personal fantasies, communicative memories, oral storytelling, sensuous memories, and family anecdotes. It is therefore set in a hyper-real space, where cinematic meaning is shaped by such counter-discourses as alternative histories, bodily memories, and bodily practices.

As László Strausz has apply demonstrated, Taxidermia does not only stage the body "as a memory site" (1), but also "each of the episodes selects a recurring, performative corporeal practice" (1) that becomes principal carriers of cinematic meaning, creating sensuous, corporeal, non-hegemonic counter-narratives. In case of the grandfather this practice is sexuality (reproduction), in case of the father it is eating, whereas in case of the son it is defecation (dealing with excrement and dead bodies) [Figs. 5-6]. From the point of view of the film's strategies of distancing from official ideologies and historical narratives it may be important to note that all three characters are overpowered by other people or by larger historical forces, all three are losers in different ways, and their outsider-existence is further emphasised by the questionable nature of the filial relationships, as the spectator may have serious doubts about the real fathers of both the fast-eating and the taxidermist Balatonys. In other words, Taxidermia undermines the idealized figure of the human being (inherited from humanism) and the narratives of official, "falsely redemptive" history (Lowenstein 2005, 146) by relying on bastard-narratives and the material practices of the human body. Similarly to Hukkle, Taxidermia also often applies haptic images. Its goal seem to be less radical perhaps: it does not dissolve human beings and human stories in a phenomenal world of sensory experiences, but "only" undermines hegemonic discourses about humans (and especially masculinities) by its haptic images and unusual perspectives.

By basing the characters on corporeal discourses, calling attention to the haptic, phenomenal characteristics of the characters' life-worlds, using non-idealizable bodies, and relying on non-melodramatic acting, Taxidermia, similarly to Hukkle, also effectively distances itself from that sort of idealizing representation that (from as early as the Greeks) regards the bodily, the physical, the material, and the visible as secondary to the spiritual, non-material, and non-visible. 


\section{The Senses against Sense: The Hermeneutics of the Surface}

In his already quoted article Strausz argues that Taxidermia "addresses the issue of historical (dis)continuity" (1), without doubt a key element of Eastern-European historicity. This discontinuity (well signified by the brokenness of the patriarchal family lineage and the circling camera-work) obviously marks a distance from the grand narratives of an idealized, redemptive History. However, as I have already suggested, this is not the only means of the two films that serves the purpose of creating narratives and cinematic worlds more or less detached from hegemonic historical narratives. The little village of Hukkle, out of time, history and symbolic meaning, and the heterogeneous, hybrid, hyper-realistic worlds of Taxidermia, where fantasy and history, sensuous memory and corporeality interact in rich, but unreliable narratives are both distanced from (logocentric, idealized) Meaning as a result of their haptic visuality and sensuousness.

Though in the above quoted article Strausz performs a fairly successful "symptomatic-thematic reading" (2) of Taxidermia, interpreting the sexualized body as a symptom of social subjugation, and (following a similar hermeneutic tradition) Teréz Vincze in her review assumes that the point of Hukkle is to "tell a crime story with the help of its slowly flowing images" $(2002,113)$, I would argue that both films play tricky games with interpretation: with the help of the above mentioned cinematic strategies they create a distance from symptomatic readings and story-based understanding. In my opinion, one of the most exciting cinematic characteristics of Pálfi's films is the way they play off the images' haptic sensuousness against symbolic, conceptual, and narrative understanding, that is, how they use the senses to undermine sense, the Logos and control over cinematic meaning.

Vincze's above mentioned review apply shows the situation's ambiguities. On the one hand, she highlights the visual-sensuous strength of Hukkle, and - in order to contextualise it - distinguishes films that rely on the power of images from others that focus on narrative. However, on the other hand, she supposes that the aim of these powerful images, at the end of the day, is to tell a story. According to her, in Hukkle "imagery transubstantiates into narrative" (2002, 115), which statement, from the point of view of (post-)deconstructive picture theory, is equal to subjugating the sensuous power of images to the reign of the sublime Logos, privileging sense over the sensuous. The expression transubstantiate [átlényegül] clearly expresses this metaphysical heritage in which aesthetic phenomena must make sense, must 
take up its place within the supreme Logos so as to be acknowledged. Vincze, of course, follows a long tradition of European modernist aesthetics when she holds those films in the highest esteem that simultaneously take images seriously and tell stories, films that "fill up images with thoughts" $(2002,115)$.

Though my personal tastes may very well coincide with those of Vincze, I would argue that Hukkle (and partly Taxidermia as well) share some experimental qualities and open a more or less new chapter in contemporary Hungarian filmmaking precisely because they wish to break loose from the Logos: the sensual impressions they make often deliberately exceed the realm of sense, they create a surplus of multisensory affect that cannot be contained in the realm of conceptual or narrative meaning. I agree with such film theoreticians as Steven Shaviro, who argue (throughout The Cinematic Body, 1993, for example) that cinema always produces such an affective surplus; yet, I think in Pálfi's films this also becomes a strategy to avoid, bypass, or radically destabilize logocentric meaning. Pálfi's films play complex, ambiguous games with meaning and interpretation: they are simultaneously seductive film-texts, calling on interpretation in order to find meaning where meaning is clearly endangered (as Vincze has rightly observed), yet through the above listed formal qualities they also make sure that such attempts can never reach totalizing conclusions.

Interestingly, Vincze also quotes a sentence from Béla Balázs that points out precisely this anti-metaphysical "flatness" of the film (so as to use Laurent Berlant's term), its difference from the hermeneutic tradition that cannot help seeking for a secret, underlying, logocentric, "deep" meaning: "Film is the art of the surface... the psychology and the significance of film are not based on the 'deeper content' of thoughts: they are always visible to the eye and completely perceivable on the surface" (Vincze 2002, 114). In my opinion, Taxidermia and Hukkle are par excellence examples of this sort of "flat" signification that avoids the hermeneutic of depth through the overabundance of non-narrative sensuous impressions.

From a historical perspective, one could argue that film's surface-based signification took time to be recognized. In a two thousand years old hermeneutical tradition that has been obsessed with "the beyond" from Plato and Aristotle on, the "art of surface" is definitely something new. Plato's cave may take on new significance from this point of view: Plato's "prisoners," tied down in the cave, watching the mime show (staged by Plato as deceived fools for not understanding the origin of the shadows on the cave's wall) may be the only ones in this setting who actually take sensuous impressions (images) seriously: the wise "philosopher" (the prototype of the Western intellectual), who wishes to lead these people from 
sensuous illusion to the invisible truth of the Logos, is someone who has never given oneself over to the lure of the moving images. The philosopher looks at these fleeting, material, sensory impressions only in order to find something behind them, use them as symptoms of an underlying other meaning, some sort of immaterial, invisible, “deep,” and usually universal meaning.

The influence of this kind of symptomatic interpretation or hermeneutics of depth in cinema studies has not vanished in the $20^{\text {th }}$ century with the birth of such anti-metaphysical intellectual trends as postmodernism, poststructuralism, or deconstruction. Psychoanalytic film theory and criticism - maybe often in spite of its intentions - have further prolonged its influence. The concept of the unconscious, the distinction between latent and manifest meaning, and the practice of symptomatic reading (that leads from manifest to latent, surface to depth, sensorial to sense) have effectively extended the life of this old hermeneutical model that has always been sceptical and even hostile towards the sensual, the material, and the affective. Jonathan Culler's words about "symptomatic interpretation" summarize well one's possible theoretical reservations about the above mentioned hermeneutics of depth: “'symptomatic' interpretation [...] treats the text as the symptom of something non-textual, something supposedly 'deeper,' which is the real source of interest [...]. Symptomatic interpretation neglects the specificity of the object - it is a sign of something else - and so is not very satisfying as a mode of interpretation" $(1997,69)$.

Pálfi's body cinema (and Gergely Pohárnok's camera-work) produce such richly sensuous surfaces, abound in such strongly affective, yet non-narrative elements, that undermine the legitimacy of symptomatic interpretation. These images may or may not play roles in story-telling, may or may not be filled up with thoughts, but they constantly call attention to the affective-sensuous dimension of cinema, to that realm of meaning that lies beyond the reach of the Logos, that is, to the visible realm lying naked, unconcealed, on the surface, here right in front of our eyes. This visible, non-logocentric, non-metaphysical surface takes the viewer to a hyper-realistic jungle of multisensory impressions that evoke corporeal memories from the Eastern-European spectator. They evoke the local sensorium, together with its bodily-based, non-controllable habitus, a whole way of being in the world, a complex, yet unreflected approach that makes the cinematic experience for most Eastern-European viewers an especially unique, strongly affective experience. 


\section{References}

Berlant, Laurent. 2012. Structures of Unfeeling: Mysterious Skin. Keynote lecture at the $3^{\text {rd }}$ International RHSS Conference in Zadar, Croatia, on $6^{\text {th }}$ Spetember, 2012.

Bourdieu, Pierre.1990. The Logic of Practice. Stanford: Stanford University Press. Culler, Jonathan. 1997. Literary Theory: A Very Short Introduction. Oxford: Oxford University Press.

Geurts, Kathryn Linn. 2002. Culture and the Senses. Bodily Ways of Knowing in an African Community. Berkeley: University of California Press.

Kalmár György. What the body remembers. The Memories of Eastern-European Body Cinema: Pálfi György's Taxidermia. Loci Memoriae Hungaricae - The Theoretical Foundations of Hungarian "lieux de mémoire" Studies. To be published, Debreceni Egyetemi Kiadó.

Lakoff, George, Mark Johnson. 1980. Metaphors We Live By. Chicago: U of Chicago P. Lowenstein, Adam. 2005. Shocking Representations: Historical Trauma, National Cinema and the Modern Horror Film. New York: Columbia University Press.

Marks, Laura U. 2000. The Skin of the Film: Intercultural Cinema, Embodiment, and the Senses. Durham and London: Duke University Press.

Strausz László. 2011. Archaeology of Flesh: History and Body-Memory. Taxidermia. Jump Cut no. 53 (Summer)

http://www.ejumpcut.org/archive/jc53.2011/strauszTaxidermia/. Last accessed at 12. 03. 2014.

Vincze Teréz. 2002. Gondolkodó képek. Pálfi György Hukkle címú filmjéről. Dunánál no. 10: 113-115. 


\section{List of Figures:}

Figures 1-4. György Pálfi: Hukkle (2002).
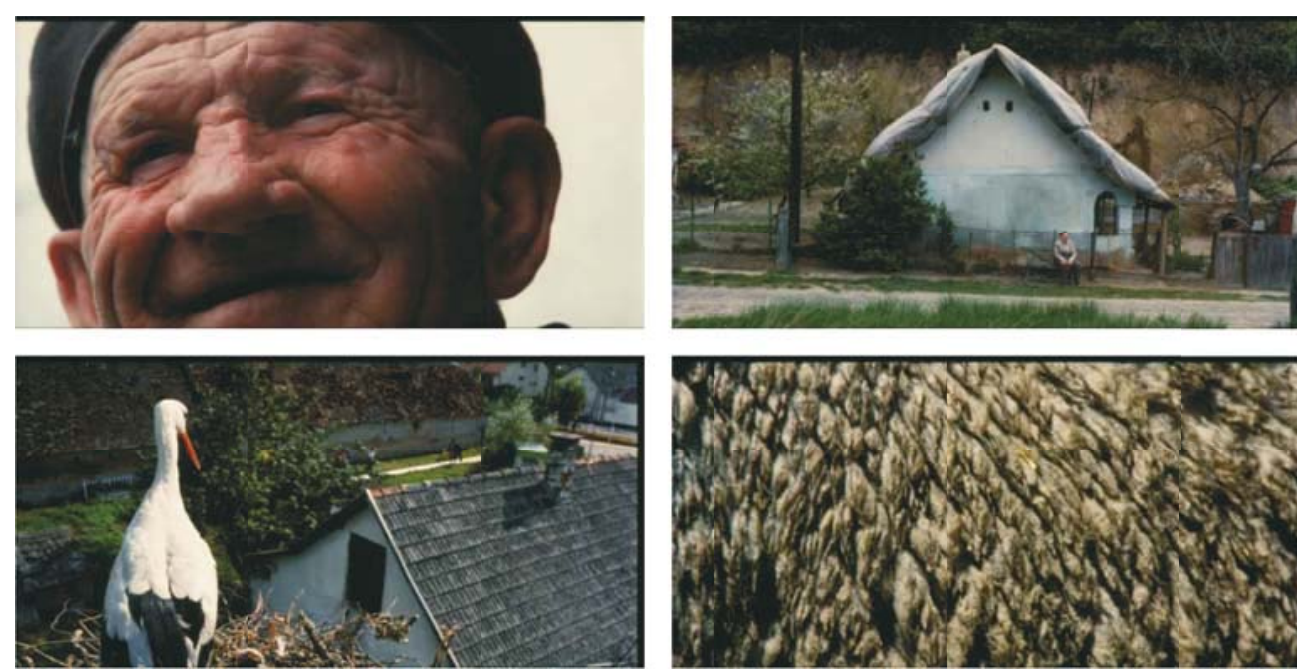

Figures 5-6. György Pálfi: Taxidermia (2006).
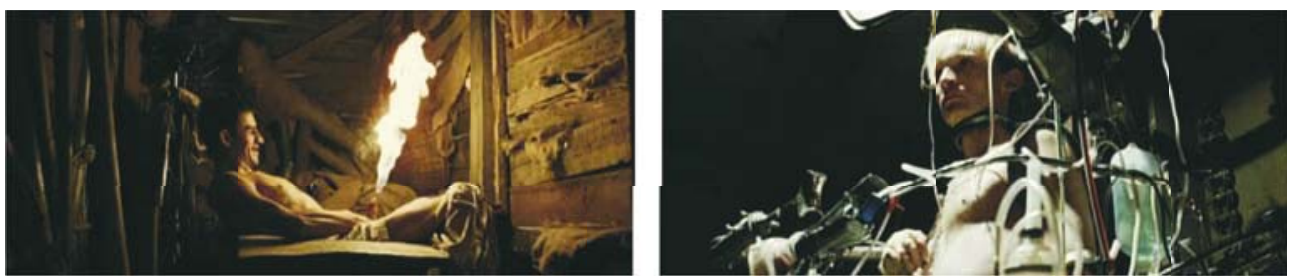